\title{
Sperm proteasome and fertilization
}

\author{
Peter Sutovsky \\ Division of Animal Sciences, and Department of Obstetrics, Gynecology and Women's Health, University of \\ Missouri-Columbia, Columbia, Missouri 65211-5300, USA
}

Correspondence should be addressed to P Sutovsky; Email: sutovskyp@missouri.edu

\begin{abstract}
The omnipresent ubiquitin-proteasome system (UPS) is an ATP-dependent enzymatic machinery that targets substrate proteins for degradation by the $26 \mathrm{~S}$ proteasome by tagging them with an isopeptide chain composed of covalently linked molecules of ubiquitin, a small chaperone protein. The current knowledge of UPS involvement in the process of sperm penetration through vitelline coat (VC) during human and animal fertilization is reviewed in this study, with attention also being given to sperm capacitation and acrosome reaction/exocytosis. In ascidians, spermatozoa release ubiquitin-activating and conjugating enzymes, proteasomes, and unconjugated ubiquitin to first ubiquitinate and then degrade the sperm receptor on the VC; in echinoderms and mammals, the VC (zona pellucida/ZP in mammals) is ubiquitinated during oogenesis and the sperm receptor degraded during fertilization. Various proteasomal subunits and associated enzymes have been detected in spermatozoa and localized to sperm acrosome and other sperm structures. By using specific fluorometric substrates, proteasome-specific proteolytic and deubiquitinating activities can be measured in live, intact spermatozoa and in sperm protein extracts. The requirement of proteasomal proteolysis during fertilization has been documented by the application of various proteasome-specific inhibitors and antibodies. A similar effect was achieved by depletion of sperm-surface ATP. Degradation of VC/ZP-associated sperm receptor proteins by sperm-borne proteasomes has been demonstrated in ascidians and sea urchins. On the applied side, polyspermy has been ameliorated by modulating sperm-associated deubiquitinating enzymes. Diagnostic and therapeutic applications could emerge in human reproductive medicine. Altogether, the studies on sperm proteasome indicate that animal fertilization is controlled in part by a unique, gamete associated, extracellular UPS.
\end{abstract}

Reproduction (2011) 142 1-14

Introduction: casting the $26 \mathrm{~S}$ proteasome in the role of mammalian egg coat lysin

The fertilizing mammalian spermatozoon binds to the egg coat, zona pellucida (ZP), undergoes acrosomal exocytosis (AE), forms the acrosomal shroud, and penetrates the zona to fuse with the oocyte plasma membrane, the oolemma. Despite decades of research, the mechanism by which the fertilizing spermatozoon penetrates the zona remains one of the fundamental unexplained mechanisms in fertilization and developmental biology. The identity of 'zona lysin', the sperm acrosomal enzyme that digests the fertilization slit in the ZP, postulated in the late 1950s by Austin \& Bishop (1958) remains unknown to us. Consequently, physical and enzymatic forces participating in spermzona penetration have been a subject of spirited debate (Green 1987, Bedford 1998, 2008, Olds-Clarke 2003). Recent work from several laboratories introduced the $26 \mathrm{~S}$ proteasome as a candidate for ascidian, echinoderm (sea urchin), and mammalian egg coat lysin (reviewed by Sakai et al. (2004) and Zimmerman \& Sutovsky (2009)). In addition to being implicated in the process of sperm-zona (or vitelline coat (VC)) penetration, a role has been postulated for sperm acrosome-borne proteasomes in the process of sperm capacitation and sperm acrosome reaction (AR/AC; Morales et al. 2007, Chakravarty et al. 2008). The goal of this review is to summarize and interpret the findings that support the participation of sperm-borne proteasomes in mammalian fertilization. Observations in support of proteasome-dependent fertilization mechanism include: 1 ) detection of various proteasomal subunits in the sperm acrosome of various mammalian species; 2) inhibition of mammalian fertilization by specific proteasomal inhibitors and anti-proteasome antibodies; 3) measurement of proteasome-associated proteolytic and deubiquitinating activities recorded in the live mammalian spermatozoa; 4) presence of anti-proteasome antibodies in sera of men suffering from autoimmune infertility; and 5) emerging evidence of infertile transgenic rodents carrying mutations of genes in the ubiquitin-proteasome system. To completely understand the meaning of fertilization experiments aimed at altering the gamete ubiquitin-proteasome system (UPS), let us first venture in more detail into the general workings of this pathway. 


\section{Ubiquitin-proteasome system}

The ubiquitin-proteasome system (Fig. 1) is responsible for regulated, substrate-specific proteolysis of $\sim 75 \%$ of all eukaryotic proteins. Ubiquitin is a small chaperone protein that covalently modifies other proteins and marks them for degradation by the $26 \mathrm{~S}$ proteasome, a multisubunit protease. Ubiquitin, the most highly conserved eukaryotic protein, is composed of 76 amino acid residues. In particular, seven of these are Lys-residues (K6, K11, K27, K29, K33, K48, and K63) to which other ubiquitin molecules bind in tandem fashion to form the isopeptide-bonded multi-ubiquitin chains. Although the multi-ubiquitin chain formation can be initiated at any of these seven Lys-residues, $\mathrm{K} 48$ is the most common linkage site for tetra and polyubiquitin chains recognized by the $26 \mathrm{~S}$ proteasome and $\mathrm{K} 63$ is the most common site of diubiquitination targeting membrane receptors for lysosomal degradation.

Ubiquitination is an orchestrated series of enzymatic reactions, some of which require ATP. It starts with the activation of unconjugated monoubiquitin with ubiquitin activating enzyme E1 (UBE1), a conserved enzyme that requires phosphorylation in order to become active. There is perhaps no coincidence that E1 was found among proteins that are phosphorylated during sperm capacitation in the rat (Baker et al. 2010). The UBE1 is subsequently dislodged from activated ubiquitin and replaced with ubiquitin carrier/ubiquitin conjugating enzyme E2. There are about a dozen E2-type enzymes in mammals. In particular, a testis-specific E2 enzyme, UBE2R is present in spermatozoa of the ascidian Ciona intestinalis (Yokota et al. 2010), and a testis-specific isoform of E2 enzyme UBC4 has been identified in rat (Wing et al. 1996). Concurrent with ubiquitin binding to UBE2, the protein substrate destined for ubiquitination and proteasomal degradation is sought out and engaged by an E3-type ubiquitin ligase, of which there are several hundred species in mammals, and a multitude expressed in male germ line and present in spermatozoa (supplemental data in Baker et al. (2008)). Ubiquitin ligases have been classified into two major groups: the RINGfinger containing ones and the HECT-domain containing ones (Glickman \& Ciechanover 2002). They are the enzymes responsible for the substrate specificity of protein ubiquitination, identifying protein substrates that carry specific degron sequences and protein molecules that are misfolded or otherwise compromised. The E3-ligases catalyze covalent ligation of the C-terminal Gly-residue (G76) of ubiquitin to an internal Lys-residue (-K-) of the substrate protein. Subsequent to this substrate monoubiquitination, the ubiquitin chain elongates, resulting in a multi-ubiquitin chain formed on the 'ubiquitinated' substrate protein. Ubiquitin chain elongation at this stage may be aided by elongating factors, including enzymes E4 or U-box containing proteins (Glickman \& Ciechanover 2002).
A multi-ubiquitin chain containing four or more ubiquitin molecules is a consensus signal for proteasomal degradation, serving as a homing signal recognized by the $19 \mathrm{~S}$ proteasomal regulatory complex subunit PSMD4 (Young et al. 1998, Wilkinson et al. 2000). Following the docking of ubiquitinated protein substrate to the $26 \mathrm{~S}$ proteasome, the multi-ubiquitin chain is freed and disassembled, so individual ubiquitin molecules can re-enter the cycle of protein ubiquitination and degradation. The protein substrate is then primed for degradation in the proteasomal $19 \mathrm{~S}$ regulatory complex and threaded through the barrel-shaped $20 \mathrm{~S}$ proteasomal core, in which it is degraded by resident protease subunits. Proteasome breaks proteins into peptides of up to 25 amino acid residues that are released and subjected to disassembly by cytosolic endopeptidases (Voges et al. 1999).

\section{Composition and function of the $26 \mathrm{~S}$ proteasome}

The $26 \mathrm{~S}$ proteasome is a multi-subunit protease with specific affinity for ubiquitin-tagged proteins (Fig. 2). Canonical $26 \mathrm{~S}$ proteasome is composed of a hollow $20 \mathrm{~S}$ core capped on one or both ends with a 19S regulatory particle. The role of $19 \mathrm{~S}$ particle is to recognize and engage the multi-ubiquitin tail attached to a protein destined for proteasomal degradation. The multi-ubiquitin chain is removed by the 19S subunits with deubiquitinating activity or by extrinsic deubiquitinating enzymes that can associate with the 19S complex. Then, the substrate protein is unfolded and translocated to the $20 \mathrm{~S}$ core. As the primed protein enters the core, it is broken into small peptides that are released from the $20 \mathrm{~S}$ core. Nomenclature of proteasomal subunits is shown Table 1, including Human Genome Organization (HUGO) nomenclature and systematic nomenclature compiled by Coux et al. (1994) and Tanaka (2009).

\section{$20 S$ core particle}

$20 S$ core particle (20S CP or 205 core) is composed of four concentric rings, each composed of seven subunits, together forming a hollow barrel-shaped structure. It is within the hollow lumen of $20 \mathrm{~S}$ core that the proteolysis of substrate proteins occurs. The outer two rings are composed of subunits PSMA1-7 ( $\alpha$-type subunits $1-7$ ) that connect the core to the base of 19S complex. The two inner rings are composed of subunits PSMB1-7 ( $\beta$-type subunits $1-7$ ). The actual threonine protease activities, including the caspaselike/peptidyl-glutamyl-peptide hydrolyzing (PGPH), trypsin-like, and chymotrypsin-like activity, reside in three catalytic $\beta$-type subunits: PSMB6 ( $\beta 1)$, PSMB7 $(\beta 2)$, and PSMB5 ( $\beta 5)$. Immunoproteasomes, the specialized proteasomes mainly involved in antigen 
presentation by the cells of immune system, replace these three constitutive $\beta$-subunits with alternative, interferon-inducible subunits designated PSMB9 ( $\beta 1 \mathrm{i}$ or LMP2), PSMB10 ( $\beta 2 \mathrm{i}, \mathrm{LMP10}$, or MECL-1), and PSMB8 (35i or LMP7; Kloetzel \& Ossendorp 2004). Of interest to the present review, all three immunoproteasome subunits have been detected in boar spermatozoa (Sutovsky et al. 2004).

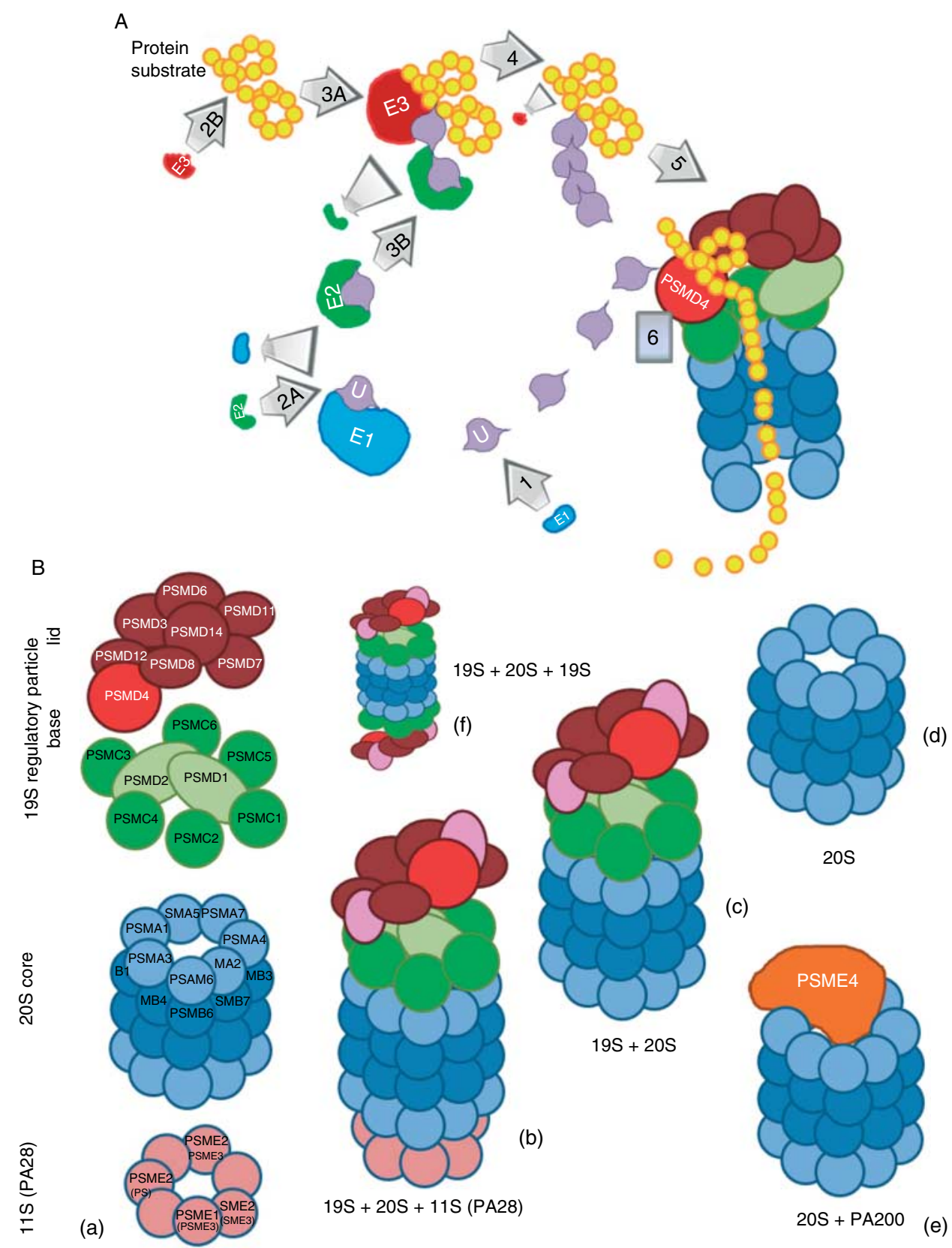

Figure 1 (A) Diagram of protein ubiquitination and degradation by the $26 \mathrm{~S}$ proteasome. (Step 1) Phosphorylated ubiquitin activating enzyme E1 (UBE1) activates a single ubiquitin molecule. (Step 2A) UBE1 is supplanted by ubiquitin carrier enzyme/ubiquitin conjugating enzyme E2. (Step 2B) Substrate protein is flanked by an E3-type ubiquitin ligase. (Step 3A) Ubiquitin ligase E3 covalently links the activated ubiquitin molecule to an internal Lys-residue of the substrate protein. (Step 3B) Second activated ubiquitin molecule is linked to substrate bound ubiquitin. (Step 4) Ensuing tandem ligation of additional activated ubiquitin molecules results in the formation of a multi-ubiquitin chain. (Step 5) Multi-ubiquitin chain of four or more ubiquitin molecules is recognized and engaged by subunit PSMD4 of the 19S proteasomal regulatory complex. (Step 6) Substrate protein is deubiquitinated (liberated ubiquitin molecules re-enter the cycle), unfolded, transferred to $20 \mathrm{~S}$ core, and broken into small peptides, released from the $20 \mathrm{~S}$ core lumen. (B) Variations on the subunit composition of the $26 \mathrm{~S}$ proteasome. (a) Subunit makeup of the (top to bottom) $19 \mathrm{~S}$ regulatory particle (lid+base), 20S core, and 11S particle (PA28). (b) 20S core capped with $19 \mathrm{~S}$ particle on one side and an 11S complex/PA28 on the other. (c) $20 \mathrm{~S}$ core capped with one 195 particle. (d) Uncapped 20S proteasome. (e) $20 \mathrm{~S}$ core capped with proteasome activator PA200. (f) Canonical 26S proteasome, with one 195 particle/cap on each side of $20 \mathrm{~S}$ core. 

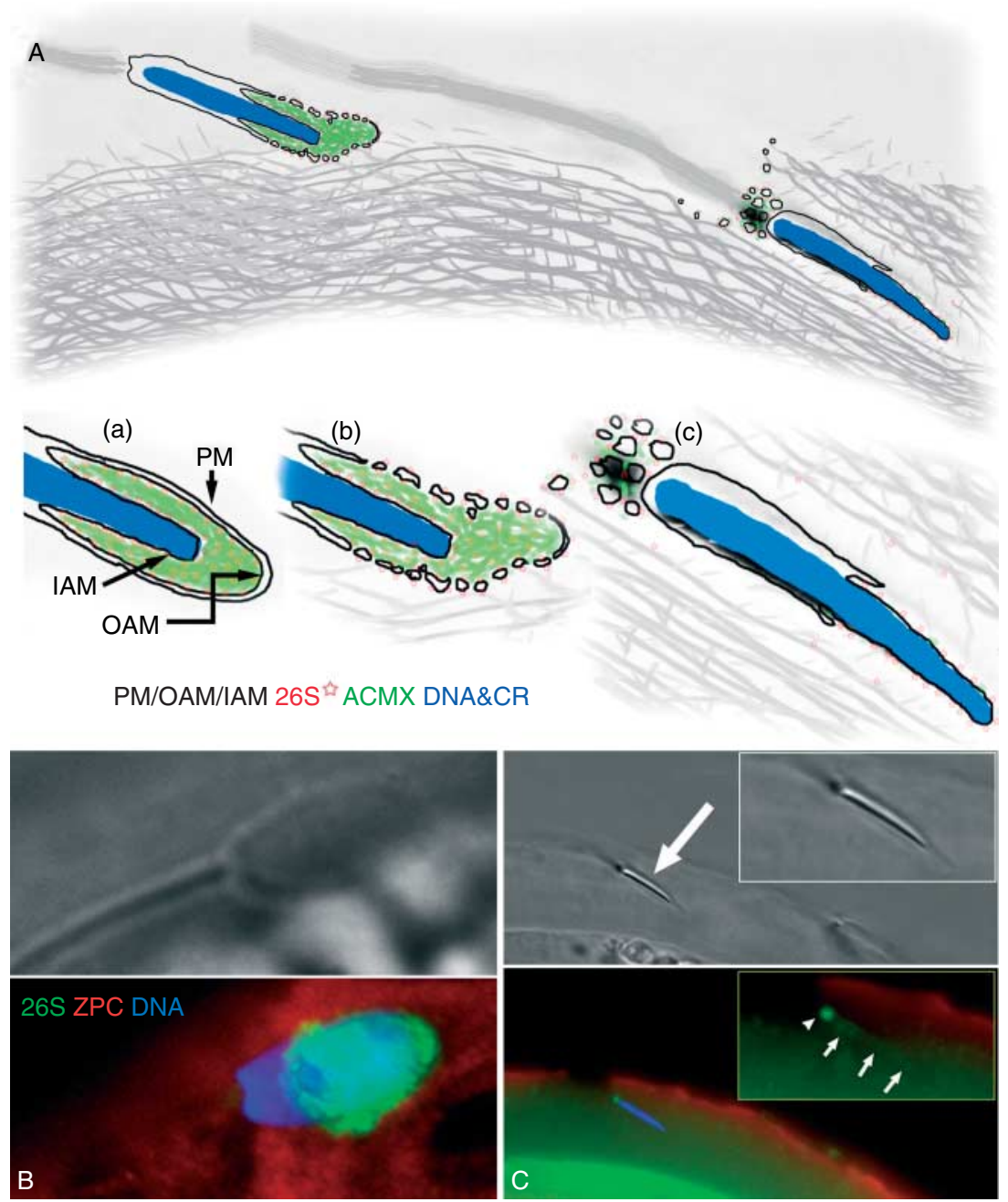

Figure 2 Acrosome remodeling and proteasome localization during the zona pellucida-induced acrosome reaction in the pig IVF system. (A) Diagram based on immunofluorescence and transmission electron microscopy images of boar sperm acrosomal exocytosis. In an intact acrosome (a), proteasomes (red star) are bound to inner (IAM) and outer (OAM) acrosomal membranes and also dispersed throughout acrosomal matrix (ACMX; green). It is not clear whether there are proteasomes anchored to plasma membrane (PM) overlying the OAM of boar spermatozoa, although studies suggest that this is the case in human spermatozoa (Morales et al. 2004). On sperm-zona binding, the IAM and OAM give rise to acrosomal membrane vesicles coated with proteasomes (b), which together with loosened ACMX form a zona-bound acrosomal shroud, a transient but structurally stable structure (Sutovsky et al. 2004, Yi et al. 2007b). During sperm-zona penetration, (c) remnants of the acrosomal shroud envelope the sperm tail connecting piece, while a subpopulation of proteasomes remain associated with IAM. Presence of proteasomes in the IAM has been demonstrated by biochemical fractionation of boar acrosomal membranes (Yi et al. 2010). (B) Immunodetection of proteasomes (green) in the acrosomal shroud of a zona bound, acrosome-reacted boar spermatozoon. Sperm receptor protein ZPC is labeled red; DNA is counterstained blue with DAPI (see study by Zimmerman et al. (2011)) for detailed materials and methods). (C) Proteasomes (green) are detected on the IAM (arrows) and in the cluster of acrosomal membrane vesicles associated with the sperm tail connecting piece (arrowhead) in a spermatozoon passing through ZP (red; anti-ZPC antibody). Top panels in fig. B and C are parfocal images of the same spermatozoa photographed using differential interference contrast (DIC).

\section{$19 S$ regulatory particle}

$19 S$ regulatory particle (19S RP, 195 complex, or PA700) forms a cap on one or both ends of the $20 \mathrm{~S}$ core. The $19 \mathrm{~S}$ particle is composed of a base and a lid. The base, attached to the outer ring of 20S core, is composed of 14 non-ATPase subunits (PSMD1-14). In particular, subunit PSMD4 (RPN10) is responsible for the recognition and binding of multi-ubiquitin chains. Of the total PSMD subunits, eight share conserved MPN and PCI domains with the subunits of the COP9 signalosome, a protein complex involved in various regulatory functions, including regulation of proteasomal proteolysis via protein deubiquitination and deneddylation (Kato \& Yoneda-Kato 2009). The lid of 19S RP is composed of six ATPase subunits (PSMC1-6), thought to participate in substrate unfolding and translocation to 205 core.

\section{Alternative 'caps'}

Alternative 'caps' replacing the 19S RP in certain types of proteasomes include proteasome activator particles 
Table 1 Proteasomal subunit nomenclature, inducible 20S core $\beta$-subunits are in italics, and the 19S subunit responsible for ubiquitin chain recognition in bold.

\begin{tabular}{|c|c|c|}
\hline & $\begin{array}{l}\text { HUGO nomen- } \\
\text { clature (human } \\
\text { gene/protein name) }\end{array}$ & $\begin{array}{l}\text { Systematic nomen- } \\
\text { clature (Coux et al. } \\
\text { 1994, Tanaka 2009) }\end{array}$ \\
\hline \multirow[t]{7}{*}{$20 S$ core $\alpha$-subunits } & PSMA1 & Subunit $\alpha-6$ \\
\hline & PSMA2 & Subunit $\alpha-2$ \\
\hline & PSMA3 & Subunit $\alpha-7$ \\
\hline & PSMA4 & Subunit $\alpha-3$ \\
\hline & PSMA5 & Subunit $\alpha-5$ \\
\hline & PSMA6 & Subunit $\alpha-6$ \\
\hline & PSMA7 & Subunit $\alpha-4$ \\
\hline \multirow{7}{*}{$\begin{array}{l}\text { Constitutive 20S core } \\
\beta \text {-subunits }\end{array}$} & PSMB1 & Subunit $\beta-6$ \\
\hline & PSMB2 & Subunit $\beta-4$ \\
\hline & PSMB3 & Subunit $\beta-3$ \\
\hline & PSMB4 & Subunit $\beta-7$ \\
\hline & PSMB5 & Subunit $\beta-5$ \\
\hline & PSMB6 & Subunit $\beta-1$ \\
\hline & PSMB7 & Subunit $\beta-2$ \\
\hline \multirow{3}{*}{$\begin{array}{l}\text { Inducible } 205 \text { core } \\
\beta \text {-subunits }\end{array}$} & PSMB8 & Subunit $\beta-5 i$ \\
\hline & PSMB9 & Subunit $\beta-1 i$ \\
\hline & PSMB10 & Subunit $\beta-2 i$ \\
\hline \multirow{6}{*}{$\begin{array}{l}\text { 19S complex ATPase } \\
\text { subunits }\end{array}$} & PSMC1 & Subunit Rpt2 \\
\hline & PSMC2 & Subunit Rpt1 \\
\hline & PSMC3 & Subunit Rpt5 \\
\hline & PSMC4 & Subunit Rpt3 \\
\hline & PSMC5 & Subunit Rpt6 \\
\hline & PSMC6 & Subunit Rpt4 \\
\hline \multirow{14}{*}{$\begin{array}{l}\text { 19S complex non-ATPase } \\
\text { subunits }\end{array}$} & PSMD1 & Subunit Rpn2 \\
\hline & PSMD2 & Subunit Rpn1 \\
\hline & PSMD3 & Subunit Rpn3 \\
\hline & PSMD4 & Subunit Rpn10 \\
\hline & PSMD5 & N/A \\
\hline & PSMD6 & Subunit Rpn7 \\
\hline & PSMD7 & Subunit Rpn8 \\
\hline & PSMD8 & Subunit Rpn12 \\
\hline & PSMD9 & Subunit Rpn4 \\
\hline & PSMD10 & $\mathrm{N} / \mathrm{A}$ \\
\hline & PSMD11 & Subunit Rpn6 \\
\hline & PSMD12 & Subunit Rpn5 \\
\hline & PSMD13 & Subunit Rpn9 \\
\hline & PSMD14 & Subunit Rpn11 \\
\hline \multirow[t]{3}{*}{ 11S complex (PA28) } & PSME1 & Subunit PA28 $\alpha$ \\
\hline & PSME2 & Subunit PA28 $\beta$ \\
\hline & PSME3 & Subunit PA28 $\gamma$ \\
\hline $\begin{array}{l}\text { Proteasome activator } \\
\text { PA200 }\end{array}$ & PSME4 & N/A \\
\hline
\end{tabular}

PA200 and PA28, the latter known commonly as 11S regulatory particle, $11 \mathrm{~S}$ regulatory complex, or REG. The PA200 particle is a single molecule of $200 \mathrm{kDa}$ proteasomal subunit protein PMSE4. Associated with immunoproteasomes (Kloetzel \& Ossendorp 2004), the PA28 is a heptamer composed of either seven molecules of proteasomal subunit PSME3 (PA28 $\gamma$ ) or heterodimers of subunits PSME1 (PA28 $\alpha$ ) and PMSE2 (PA28 $\beta$ ). Both PA28 and PA200 can associate with 205 core, forming hybrid proteasomes. Such proteasomes may be able to degrade proteins that are not tagged with ubiquitin, though this scenario is not definitively established (Rechsteiner \& Hill 2005).

In summary, proteasomes can be found in cells as canonical $26 \mathrm{~S}$ proteasomes capped with one or two $19 \mathrm{~S}$ complexes, 20S proteasomes capped with an $11 \mathrm{~S}$ regulatory complex, 20S proteasomes capped with PA200, or uncapped 20S proteasomes (Fig. 2). Such distinctly configured proteasomes differ in their tissue distribution, subcellular localization, and function.

\section{Spermatozoa carry enzymatically active proteasomes}

Sperm-borne proteasomes were first identified in ascidians in the early 1990s (Saitoh et al. 1993). Since then, it became obvious that proteasomes are present in both non-mammalian and mammalian spermatozoa and they regulate fertilization, particularly the process of sperm penetration of the VC (reviewed by Sakai et al. (2004) and Zimmerman \& Sutovsky (2009)). Reciprocal to the presence and activity of proteasomes in spermatozoa, substrates for proteasomal degradation are present on the egg coat in the form of ubiquitinated sperm receptor proteins in echinoderms (Yokota \& Sawada 2007b), ascidians (Sawada et al. 2002a) and mammals (Sutovsky et al. 2004, Zimmerman et al. 2011). Consequently, proteasomal inhibitors and other agents that interfere with sperm proteasome function (antibodies, peptides, and mutant ubiquitin) efficiently and sometimes completely inhibit mammalian and nonmammalian fertilization alike (reviewed by Sakai et al. (2004), Yi et al. (2007a) and Zimmerman \& Sutovsky (2009)). Due to unique structural and functional features of the mammalian sperm acrosome, sperm acrosomal proteasomes are extracellularly located, i.e. tethered to acrosomal surface in humans (Morales et al. 2004), rodents (Pasten et al. 2005), and ungulates (Sutovsky et al. 2004, Yi et al. 2009a). Proteasomes probably become associated with sperm's inner and outer acrosomal membranes (OAM) during acrosomal biogenesis at the spermatid stage (Rivkin et al. 2009). Consequently, it appears that proteasomes are exposed on the acrosomal surface of mammalian spermatozoa and able to directly interact with the ZP during fertilization (Sutovsky et al. 2004, Yi et al. 2007b, 2009a, 2009b). Retrospectively, the recent knowledge gained from fertilization experiments explains earlier observations made by spermatologists. Authors of the first study attempting to isolate the human and mouse sperm proteasomes observed that in comparison with less mature germ cells, the (mature human spermatozoa) retain relatively high values of $26 \mathrm{~S}$ proteasome activity, suggesting that they have further roles to play in normal sperm physiology' (Tipler et al. 1997). Since then, the substrate-specific enzymatic activities of $26 \mathrm{~S}$ proteasomes have been measured in spermatozoa of livestock species (Sutovsky et al. 2004, Yi et al. 2007b, 2009a, Rawe et al. 2008, Sanchez et al. 2011), humans (Morales et al. 2003, Chakravarty et al. 2008, Kong et al. 2009), and rodents (Pasten et al. 2005, Rivkin et al. 2009). The proteasomedependent mechanism of sperm VC penetration is 
apparently evolutionarily conserved as it applies to mammals (Sutovsky et al. 2004, Zimmerman et al. 2011), ascidians (Sawada et al. 2002a), and echinoderms (Yokota \& Sawada 2007 b). Evolutionary conservation of ubiquitin-dependent fertilization mechanism may reach beyond the animal kingdom to plants, where pollen adhesion and guidance seem to depend on ubiquitin (Kim et al. 2006).

\section{Why is the ubiquitin-proteasome system essential for the success of fertilization?}

Attempts to answer this question essentially rely on the use of two main model systems: the ascidian model perused by Sawada's group (also working on echinoderms) and the non-rodent, mammalian models examining gametes of humans and livestock, with some studies performed on mice. Although the presence of active proteasomes in spermatozoa appears to be well conserved, the main difference between the mammalian and the ascidian model systems is in the timing of VC ubiquitination (during fertilization versus oogenesis).

Ascidian spermatozoa are equipped with all components of the ubiquitin-proteasome system that are necessary to ubiquitinate the sperm receptor protein Halocynthia roretzi VC protein of $70 \mathrm{kDa}(\mathrm{HrVC70})$ on the ascidian VC upon sperm-egg binding. On contact with $\mathrm{VC}$, the enzymatic machinery in the ascidian sperm exudates ubiquitinates the HrVC70 protein. Subsequently, the sperm-borne proteasomes degrade the ubiquitinated HrVC70 to create a fertilization slit in the VC (Sawada et al. 2002a). Of note, the ubiquitinated ascidian sperm receptor HrVC70 is the homolog of mammalian sperm receptor protein ZPC/ZP3, a major protein of mammalian ZP (Sawada et al. 2002a). In contrast to ascidians, the sea urchin egg coat is already ubiquitinated prior to fertilization (Yokota \& Sawada 2007 b). This pattern of egg coat ubiquitination during oogenesis is similar to mammals, where ubiquitin is detectable in the ZP inside the ovarian follicles (Sutovsky et al. 2004, Zimmerman et al. 2011). To study this fertilization pathway in mammals, I mainly used the domestic pig IVF system in the laboratory (Sutovsky et al. 2004, Yi et al. 2007a, 2007b, 2009a, 2009b), as well as mouse IVF (Mtango et al. 2009) and study on human spermatozoa (Chakravarty et al. 2008). Proteomic analysis using precise, unambiguous proteomic fingerprinting of ubiquitination (Gly-Gly modification (Peng et al. 2003)) confirmed that the porcine sperm receptor protein ZPC is ubiquitinated prior to fertilization. In fact, ubiquitinated sites were identified in all the three protein components of pig ZP, i.e. ZPA, ZPB, and ZPC (Sutovsky et al. 2004, Zimmerman et al. 2011). Analysis by yeast two hybrid systems identified sperm UPAB2L, an ubiquitin-associated protein, as a likely candidate for a sperm protein that interacts with the ZP3/ZPC protein of human ZP. Accordingly, antibodies against UBAP2L inhibited human sperm-zona binding in a hemizona assay (Naz \& Dhandapani 2010).

\section{Proteasomal inhibitor studies}

Chymotrypsin-like activity of the sperm proteasomes appears to be important for VC penetration in ascidians (Saitoh et al. 1993). In accordance, MG132, a potent yet reversible widely used inhibitor of the chymotrypsin-like $20 S$ core activity, inhibits fertilization in the ascidians such as H. roretzi (Sawada et al. 2002b) and Ciona intestinalis (Sawada et al. 1998), in sea urchin Anthocidaris crassispina (Yokota \& Sawada 2007a) and Pseudocentrotus depressus (Yokota \& Sawada 2007b), and in mammals including the domestic pig (Sutovsky et al. 2003, 2004, Sun et al. 2004), cow (Rawe et al. 2008), and mouse (Wang et al. 2002). Lactacystin, a potent irreversible inhibitor affecting all three enzymatic activities of $20 \mathrm{~S}$ core, also inhibited porcine IVF (Sutovsky et al. 2004). Removal of ZP eliminated the effect of MG132 and lactacystin on porcine fertilization, an indication that these compounds specifically inhibit sperm-zona penetration step of fertilization (Sutovsky et al. 2004). Similar effect on sperm-VC penetration was observed with a related compound, MG115 in ascidian and sea urchin studies (Sawada et al. 1998, 2002b, Yokota \& Sawada 2007a, 2007 b), with lactacystin in the pig (Sutovsky et al. 2003, 2004, Sun et al. 2004) and with epoxomicin in the bovine model (Sanchez et al. 2011). Proteasome inhibition by the above compounds does not alter sperm-VC/ZP binding or sperm motility and specifically occurs at the time of sperm penetration through VC/ZP in all of the above species except the mouse, wherein fertilization was performed with zona free oocytes. Even though, the mouse spermatozoa reportedly failed to become incorporated in the ooplasm when preincubated with proteasomal inhibitor ALLN or anti-ubiquitin antibodies (Wang et al. 2002).

Mutant ubiquitin UBB +1 also inhibits porcine IVF when added to fertilization medium (Yi et al. 2010). This intrinsic proteasome-inhibiting ubiquitin species arises from a translational frame shift, resulting in a C-terminal adjunct that prevents UBB +1 from covalent ligation to Lys-residues of protein substrates or other ubiquitin molecules in the neurons of Alzheimer's patients (van Leeuwen et al. 1998, de Pril et al. 2004). When expressed in cells at a low level, UBB +1 itself becomes ubiquitinated and degraded by proteasomes. Beyond a certain threshold concentration, $U B B+1$ will saturate proteasomes, effectively causing inhibition of proteasomal proteolysis and aggregation of undegraded protein substrates, thought to be a contributing factor to Alzheimer's disease (van Leeuwen et al. 2006). The observation that $U B B+1$, a protein of $\sim 12 \mathrm{kDa}$ (hence unable to penetrate cellular plasma membrane), inhibits IVF supports the notion that sperm proteasomes are 
exposed onto sperm surface during sperm-zona interactions. In fact, binding of biotinylated proteasomal inhibitor ZL3VS, which similar to UBB +1 cannot penetrate cellular membranes, to acrosome-borne proteasomes can be visualized by indirect immunofluorescence in an IVF system (Yi et al. 2010).

\section{Anti-proteasome antibodies block IVF}

Although most published ascidian and echinoderm studies rely on proteasomal inhibitor, at least one paper shows that an anti-proteasome antibody raised by immunization with whole isolated proteasomes also inhibit fertilization/VC penetration (Sawada et al. 2002b). Anti-ubiquitin antibodies are logical candidates for inhibiting IVF. Such an approach was efficient in ascidian studies using antibody FK2, specific for K29-, K48-, and K63-linked multi-ubiquitin chains (Sawada et al. 2002a). In the mouse, both MAb and polyclonal antibodies against ubiquitinated proteins inhibited fertilization, presumably at the time of sperm-oolemma fusion since these oocytes were fertilized zona free (Wang et al. 2002). Only a slight inhibitory effect was observed on capacitation and AR.

Initial antibody inhibition studies on porcine IVF were performed with antibodies targeting multiple constitutive $20 S \alpha$ - and $\beta$-type subunit, and antibodies specific to inducible $20 S \beta$-type immunoproteasome subunits PSMB8, PSMB9, and PSMB10 (Sutovsky et al. 2004). Besides, suggesting the participation of sperm surfaceexposed proteasomes in sperm-zona penetration, such results also indicate that both the constitutive proteasomes and the immunoproteasomes may be present in the sperm acrosome. Efficient inhibition of pig IVF was also achieved using an antibody against 195 regulatory complex non-ATPase subunit PSMD4 (RPN10) (Yi et al. 2010). This subunit fulfills an essential role in proteasome-substrate recognition, as it contains the multi-ubiquitin chain-binding motifs LALAL and IAYAM (Young et al. 1998). Interestingly, antibodies to 195 nonATPase subunit PSMD8 (RPN12), thought to be involved in both multi-ubiquitin chain-recognition and substrate priming for degradation, have an opposite effect on porcine IVF; they actually drive up fertilization and polyspermy rates (Yi et al. 2009a). Possible explanation of this seeming paradox lies in the proposed involvement of this subunit in the recruitment of deubiquitinating enzymes (DUBs) to 19S complex (Stone et al. 2004), as will be discussed below.

\section{Inhibition of deubiquitination increases polyspermy during porcine IVF}

Subunit PSMD8, discussed above, associates with deubiquitinating enzyme UBP6 in yeast (Stone et al. 2004) and may serve to anchor or regulate the proteasome-associated DUBs. It has been postulated that the inhibition of deubiquitinating activity associated with the proteasomal regulatory complex will stimulate the proteolytic activities of the 20S core, resulting in accelerated protein degradation (Guterman \& Glickman 2004). In such a scenario, the deubiquitination of ubiquitin-chain-ligated protein substrate by $19 \mathrm{~S}$ complex is blocked and both the substrate and the substrate-linked multi-ubiquitin chain translocate to proteasomal core for degradation. Possible explanation of IVF results obtained with antibodies against PSMD8 is that these antibodies hindered either the proteasomal association/recruitment of a DUB or directly interfered with its deubiquitinating properties.

In a separate study (Yi et al. 2007b), an accelerated porcine fertilization and increased polyspermy were achieved using ubiquitin aldehyde (UA), a C-terminally modified full-length ubiquitin molecule that acts as a specific inhibitor of the ubiquitin C-terminal hydrolases $(\mathrm{UCHs})$. The $\mathrm{UCHs}$ are a family of DUBs involved in substrate deubiquitination as well as in the editing of multi-ubiquitin chains, which maintains a stable pool of unconjugated monoubiquitin available for ligation to substrate proteins. The UCHs are, therefore, essential for proper functioning of UPS. Members of the $\mathrm{UCH}$ family are closely related by amino acid sequence and may have an overlapping substrate specificity (Kurihara et al. 2000). However, their C-terminal hydrolase enzymatic activity varies between individual family members and a preference for certain substrates has been suggested for individual UCH family members (Kurihara et al. 2000). Of particular interest to us are UCHL1 present in the sperm acrosome and oocyte cortex, and UCHL3 present in the meiotic spindle of porcine, bovine, murine, and primate oocytes (Yi et al. 2007b, Mtango et al. 2009, Susor et al. 2010). Proteomic analysis suggests that UCHL1 is one of the most abundant proteins in mammalian oocytes (Ellederova et al. 2004, Massicotte et al. 2006). As UA is not cell permeant, its most likely target in the spermatozoa during IVF (i.e. when UA is added to fertilization medium) is UCHL1 in the sperm acrosome. An opposite effect, i.e. the amelioration of polyspermy was obtained by adding recombinant DUBs (UCHL3 and isopeptidase-T) in the porcine IVF medium (Yi et al. 2007b). Interestingly, increased polyspermy in vitro was also described in the gracial axonal dystrophy (gad) mouse carrying a function-blocking mutation of Uchl1 gene (Sekiguchi et al. 2006) as will be discussed below. In the mouse, a species in which the proteasomal inhibitors block fertilization at the oolemma (Wang et al. 2002), the addition of UA had no effect on fertilization or polyspermy rate. In contrast, preinjection of oocytes with UA or with anti-UCHL3 antibodies (UCHL1 accumulates in oocyte cortex) inhibited sperm incorporation in the ooplasm (Mtango et al. 2009). This could be due to a yet to be elucidated function of $\mathrm{UCHs}$ in the regulation of oocyte-cortical 
cytoskeleton, or to a recently demonstrated effect of UCHL1-block on cortical granule migration and maturation (Susor et al. 2010). Altogether, the above data explain why the inhibition of sperm DUBs during IVF has an effect opposite to that of IVF-blocking proteasomal inhibitors.

\section{ATP depletion affects sperm proteasomes and fertilization}

Ever since its discovery in the 1970s (Ciechanover 2009), ubiquitin-proteasome system has been commonly described as ATP dependent, with ATP being an energy donor for the chain of enzymatic reactions leading to covalent ligation of ubiquitin to protein substrates and elongation of multi-ubiquitin chains. ATP is also important for the sustenance of proteasomes because several 19S RP subunits are ATPases. This is an important consideration with regard to the postulated extracellular, sperm-surface function of proteasomes during fertilization. Knowing that ATP is predominantly an intracellular molecule, how does ATP diffuse along the sperm head surface and how is it maintained there at a concentration compatible with the functioning of the UPS?

This seeming paradox was first addressed in the ascidian fertilization system. While proteasomal proteolysis in the 20S core itself is not ATP dependent, ATP is required for proteasome integrity and function of six ATPase subunits present in the lid of 195 regulatory complex. Consequently, depletion of sperm surface ATP by potato-derived enzyme apyrase inhibited fertilization in the ascidian (Sakai et al. 2003) and the sea urchin (Yokota \& Sawada 2007b) when added to seawater during spawning. This work inspired similar experiments in the domestic pig model, where the addition of apyrase to IVF medium resulted in a reduced polyspermy and overall fertilization rate; no such effect was observed with heat-inactivated apyrase (Yi et al. 2009b). The observed reduction in polyspermic fertilization rate with $0.1 \mathrm{mg} / \mathrm{ml}$ apyrase also indicates the potential of this additive for mitigating polyspermy, a plague of porcine IVF systems. Sperm surface-associated ATP was measured by a luciferase-based assay and a change in the band pattern of proteasomal subunits in spermatozoa exposed to apyrase was captured by western blotting. As anticipated, apyrase did not reduce proteolytic activities of the $20 \mathrm{~S}$ core, which are not dependent on ATP (Yi et al. 2009b). Such results agree with recent studies showing that mouse IVF rates are improved by the addition of ATP in the IVF medium (Rodriguez-Miranda et al. 2008). The Solanum tuberosum apyrase is a large, $49 \mathrm{kDa}$ protein that is not cell permeant. If a simple addition of apyrase in fertilization milieu has an effect on sperm proteasomes, one can consider this to be an additional supporting evidence for their extracellular/ cell surface function in spermatozoa.

\section{A cell-free system to study proteasomal degradation of the mammalian sperm receptor}

It is difficult to trace the degradation of zona proteins by sperm acrosomal enzymes during sperm-zona penetration because of the minute size of the fertilization slit $(\sim 5-10 \mu \mathrm{m})$, along which this degradation occurs. Only a minute amount of zona proteins, undetectable by conventional biochemical approaches, is degraded by the zona-penetrating spermatozoa. Most likely, fewer than ten spermatozoa enter zona at one time in most fertilizable mammals in vitro. We have overcome this obstacle by developing an assay combining live, in vitro capacitated boar spermatozoa with solubilized porcine zona proteins (Zimmerman et al. 2011). On coincubation, the zona proteins bind to sperm acrosomes as they would during fertilization and induce $A E$, vesiculation of the OAM and formation of the acrosomal shroud composed of OAM vesicles and acrosomal matrix. We collect the acrosomal shrouds with partially degraded zona proteins and detect the ZP degradation products by western blotting with an antibody against porcine sperm receptor component, the zona pellucid protein ZPC. As an alternative, we replace live spermatozoa with purified sperm proteasomes. Using this method, degradation products of $<25 \mathrm{kDa}$ were detected as early as $5 \mathrm{~min}$ after the onset incubation. The formation of such ZPC degradation products was prevented by proteasomal inhibitors (Zimmerman et al. 2011). Interestingly, but perhaps not surprisingly, isolated sperm proteasomes altered the appearance/texture of intact zonae surrounding mature pig oocytes; a preincubation of metaphase II pig oocytes with boar sperm proteasomes, followed by stringent washing and IVF, resulted in reduced fertilization rates (Zimmerman et al. 2011).

\section{Role of the UPS in sperm capacitation}

Sperm capacitation serves the triplicate purpose of sperm detachment from the oviductal sperm reservoir, acrosomal surface remodeling in anticipation of zonainduced $\mathrm{AE}$, and priming of sperm membranes for the fusion with oolemma (reviewed in Gadella \& Visconti (2006) and Sutovsky (2009, 2010)). There is now evidence supporting the participation of the UPS in these events, coming both from functional studies and from analyses of sperm proteome, and sperm phosphoproteome in particular. Protein phosphorylation both on Tyr and on Ser/Thr residues is a hallmark of the capacitation process (Bailey 2010). Capacitated sperm phosphoproteome studies identified a number of UPS proteins undergoing phosphorylation during sperm capacitation in the mouse, boar, and rat. They include the ubiquitin activating enzyme UBE (Baker et al. 2010), multiple proteasomal subunits (Arcelay et al. 2008, Baker et al. 2010), the valosine-containing protein, involved in ubiquitinated substrate presentation to the $26 \mathrm{~S}$ 
proteasome (Geussova et al. 2002), and ubiquitin itself (Arcelay et al. 2008). Changes in the electrophoretic migration pattern of several $20 S$ core subunits were observed by $2 \mathrm{D}$ electrophoresis of capacitated versus non-capacitated boar spermatozoa (Choi et al. 2008).

In functional studies, the chymotrypsin-like activity of the $20 S$ proteasomal core increased during human sperm capacitation, coincident with phosphorylation of several proteasomal subunits both on Tyr and on Ser/Thr residues. Consequently, the chymotrypsin-like $20 S$ core activity was mitigated by the addition of inhibitors specific to tyrosine kinases and Ser/Thr kinases (PKA and PKC) to the capacitation medium (Kong et al. 2009). In a related study, proteasomal inhibitor epoxomicin significantly reduced protein Ser-phosphorylation during human sperm capacitation (Morales et al. 2007). This observation opens a possibility that, although regulated itself by phosphorylation, proteasomal activity may directly or indirectly control the activity of sperm-borne protein kinases. This could not only be occurring in the sperm acrosome but also in the principal piece of the sperm tail, where proteasomes could have an effect of capacitationrelated changes in sperm motility. Altogether, there is a sufficient evidence to implicate sperm proteasomes as targets and/or regulators of sperm capacitation.

\section{Proteasomal proteolysis during zona-induced AR/AE}

The classical two-state 'binary' model of 'AR' assumes that spermatozoa bind to sperm receptor ZPC and release their acrosomal content at once (reviewed by Gerton (2002)). This model predicts that AR is a rapid event without intermediary steps that occurs after the completion of sperm capacitation. The proteasomedriven fertilization paradigm is more consistent with Gerton's alternative, 'analog' model of 'AE' (Gerton 2002) that starts during capacitation (i.e. prior to sperm contact with zona). Thus $A E$ is predicted to encompass a number of intermediate states as the acrosome is shed layer-after-layer after the initial sperm-zona contact (Gerton 2002). Such an early start of, or priming for, $\mathrm{AE}$ is consistent with recent observations in transgenic mice with green fluorescent acrosomes (Jin et al. 2011). There appears to be a general agreement that the exposure/release of the acrosomal matrix occurs because of the fusion of OAM with overlying plasma membrane, resulting in the formation of hybrid vesicles (acrosomal membrane vesiculation (Yanagimachi 1994)). Acrosomal membrane vesiculation leads to the formation of the acrosomal shroud. As a stable structure composed of solid membrane vesicles and viscous acrosomal matrix, the shroud may represent a proteolysis-supporting environment with high ATP concentration around the zona-penetrating sperm head. In addition to proteasome detection on the OAM and within the acrosomal matrix, we found evidence of proteasomes coating the surface of the inner acrosomal membrane (Yi et al. 2010), the only acrosomal structure that remains patent throughout the process of sperm ZP penetration (Yanagimachi 1994). Published studies on the sperm proteasome (reviewed in Sakai et al. (2004), Yi et al. (2007a) and Zimmerman \& Sutovsky (2009)) are consistent with this model.

In human spermatozoa, both ZP- and progesteroneinduced ARs were inhibited by a specific proteasomal inhibitor, clasto-lactacystin $\beta$-lactone (CLBL; Morales et al. 2003, 2004). Human sperm incubation with fibronectin, an extracellular matrix protein present in cumulus oophorus and perivitelline space of mammalian oocytes, stimulated tyrosine phosphorylation of multiple proteasomal subunits; this coincided with $\mathrm{AE}$ and stimulation of proteasomal core enzymatic activities, measured by specific fluorometric substrates (Diaz et al. 2007). The central event of zona-induced $A E$ is calcium influx in the acrosome. It seems to be that proteasomal inhibitors inhibit AE upstream of this even in human spermatozoa coincubated with recombinant human ZP proteins. This was demonstrated by the lack of an effect of MG132 on AE induced by calcium ionophore (Chakravarty et al. 2008). Both ZP- and progesterone-induced ARs were also inhibited by CLBL. This specific inhibitor of all three $20 \mathrm{~S}$ core activities blocked the sustained phase of the $\mathrm{Ca}^{2+}$ influx in human spermatozoa, stimulated to undergo AE by zona protein or by progesterone (Morales et al. 2003).

The effect of proteasomal inhibitors on acrosomal exocytosis was studied in the boar spermatozoa coincubated with soluble porcine zona proteins (Zimmerman et al. 2011). Formation of acrosomal shrouds was monitored by flow cytometry with fluorescently tagged lectin PNA that has high affinity to glycans present on the OAM. The OAM in the pig became exposed during capacitation and the PNA labeling persisted after OAM vesiculation and formation of the acrosomal shroud induced by the coincubation of capacitated spermatozoa with solubilized porcine ZP proteins. As the acrosomal shrouds in this system have no solid matrix (i.e. intact ZP) to attach to, they eventually disintegrate - an event traceable by a decrease in PNA fluorescence of freefloating shrouds. Such a dispersion of acrosomal shroud was prevented by MG132 and other proteasomal inhibitors (lactacystin, clasto-lactacystin- $\beta$-lactone), as visualized by both flow cytometry and epifluorescence microscopy (Zimmerman et al. 2011).

One possible function of proteasomal proteolysis in the process of $\mathrm{AE}$ is in the degradation of acrosomeassociated proteins that may maintain acrosomal enzymes inactive until capacitation or AE. We have found two seminal plasma derived, acrosomal surface-bound proteins that appear to be ubiquitinated: acrosin inhibitor and spermadhesin AQN1. Co-immunoprecipitation studies on boar sperm extracts suggest that acrosin inhibitor interacts with 19S subunit PSMD4 (Yi et al. 2010). In a similar fashion, spermadhesin AQN1 
co-immunoprecipitated with 19S subunit PSMD8 (Yi et al. 2009a). Both proteins were present in an ubiquitinated protein-rich sperm protein fraction isolated by affinity purification, and both migrated on PAGE gel in a manner consistent with ubiquitination (i.e. higher than the calculated mass of the nascent proteins predicted). In an experimental system composed of capacitated boar spermatozoa and solubilized zona proteins (Zimmerman et al. 2011), the addition of proteasomal inhibitors caused the accumulation of several acrosomal proteins, including sperm adhesion molecule 1 (SPAM1), MFGE8 (aliases lactadherin, SED1, SP47), ZP binding protein 2/ZPBP2 (IAM38) and acrosinbinding protein ACRBP (SP32). In summary, multiple lines of evidence converge to support the involvement of proteasomal proteolysis in the regulation of $\mathrm{AE}$.

\section{Genetic evidence}

Mutations of genes in the UPS that affect spermatogenesis are too many to list (reviewed by Baarends et al. (2000) and Hermo et al. (2010)). Therefore, let us focus on the mutations that are permissible to production of fully differentiated spermatozoa. TMF/ARA160 is a Golgi-associated protein to which several cellular activities have been attributed. These include trafficking of Golgi-derived vesicles and E3 ubiquitin ligase activity. Null females are fertile, but males produce malformed, immotile spermatozoa lacking acrosomes, resulting in infertility (Lerer-Goldshtein et al. 2010). Similarly, males lacking the gene encoding for proteasomal activator protein PA200 produce some fully differentiated spermatozoa but are infertile due to defects in spermatogenesis and spermiation (Khor et al. 2006). Mice lacking the gene encoding for the E2-type ubiquitin conjugating enzyme HR6B display spermatid elongation defects resulting in abnormal sperm morphology and severely reduced sperm count and motility (Roest et al. 1996). Mice lacking a ubiquitin ligase-encoding gene Herc4 produce normal numbers of spermatozoa, but with reduced motility associated with the post-epididymal retention of the cytoplasmic droplet (Rodriguez \& Stewart 2007). Similar to Herc $4^{-1-}$ mice, reduced litter sizes are observed in Alox15 mice lacking the cytoplasmic droplet-associated enzyme 15lipoxygenase (15LOX), thought to cooperate with UPS during organelle recycling (Moore et al. 2010). In general, it is difficult to specifically tackle the function of sperm proteasomes during fertilization, because most mutations affecting proteasomes and associated UPS enzymes in fully differentiated spermatozoa already have an effect during spermatid elongation, thus reducing or eliminating spermiation and sperm motility.

So, is there any mutant that truly produces morphologically normal and motile spermatozoa, but has a mutation in UPS that affects sperm proteasome function during fertilization? Perhaps the closest one at present is the gad mutant mouse, a naturally occurring truncation of Uch/1 gene that causes lack of deubiquitinating activity in the mutated UCHL1 $1^{\text {gad }}$ enzyme (Saigoh et al. 1999). UCHL1, as is discussed above, accumulates in the oocyte cortex and in the sperm acrosome. The gad males display only a slight reduction of sperm concentration and motility, thought to be due to a defect in testicular and post-testicular, epididymal sperm quality control (Kwon et al. 2005, 2006). However, a reduced litter size is observed in gad females mated with wild-type males (Sekiguchi et al. 2006). It has been proposed that the reduced fertility of gad mice is in part due to misregulation of the fertilization process, particularly at the level of sperm-oolemma interactions, resulting in the increased polyspermy in vitro (Sekiguchi et al. 2006). Polyspermy, however, has not been assessed in vivo in these animals.

On the horizon is an exciting new mutant mouse lacking a gene for ubiquitin-specific peptidase/protease 2 (USP2; aliases USP9, USP41). This deubiquitinating enzyme is translated during spermatid elongation and accumulates in late elongated spermatids. Reportedly, the male Usp2 $2^{-1-}$ mice are near-completely infertile (12\% of wild-type litter size) and unable to fertilize mouse ova in vitro, in spite of having normal sperm concentration, motility (when incubated in culture media), and sperm-zona binding and AR. Contrary to wild-type spermatozoa, motility of Usp2 ${ }^{-/}$spermatozoa is reduced when cultured in PBS. Of note, removal of ZP restores the ability of Usp2 $2^{-1}$ spermatozoa to fertilize mouse ova in vitro (Bedard et al. 2011). It is thus possible that a defect induced by deletion of Usp2 gene affects both the flagellar movement and the acrosomal function necessary for sperm-zona penetration.

\section{Significance of sperm proteasome research and issues that are being resolved}

Recently, the significance of sperm proteasome studies has been highlighted in several comprehensive reviews of mammalian fertilization (Bedford 2008, Hedrick 2008, Yanagimachi 2009). The understanding of sperm proteasome and associated UPP enzymes is of significance for fertilization research, for male fertility evaluation, and for assisted reproduction in humans and livestock. It also adds to our understanding of acrosomal function and sperm-zona penetration, bringing some reconciliation to a decades-long dispute on mechanical versus enzymatic model of sperm-zona penetration. It has been discussed whether the fertilizing mammalian spermatozoon passes ZP solely because of the motile force of its flagellum, or the advancement of the sperm head through ZP matrix is aided by active enzymatic digestion of zona proteins by enzymes released from or bound to sperm acrosome (Green 1987, Bedford 1998, 2008, Olds-Clarke 2003). Studies on the sperm proteasome now offer a plausible 
candidate enzyme functioning as the zona/VC lysin during fertilization. Many intriguing questions are yet to be addressed by research on the gametic UPS. We do not know with certainty which proteasome-associated enzymatic activities are important for sperm function during livestock fertilization, although the inhibition UCH-mediated deubiquitinating activity associated with the 195 regulatory particle and the chymotrypsinlike activity of $20 S$ core both have a profound effect on mammalian IVF. In addition to proteasomes, other serine proteases may be contributing to sperm-zona penetration. Examined alone, acrosin, the original candidate for zona lysin appears to be dispensable, at least in the mouse (Baba et al. 1994). However, a double knockout of acrosin and acrosomal protease PRSS2 1 (TESP5) results in subfertile mice whose spermatozoa are completely sterile in vitro, unless exposed to uterine secretions (Kawano et al. 2010).

How are proteasomes incorporated in and anchored to the acrosome? Proteasomes are tethered to acrosomal membranes and the acrosome surface (Morales et al. 2004, Sutovsky et al. 2004, Yi et al. 2009b), most likely inserted there during acrosomal biogenesis in the spermatid (Mochida et al. 2000). We have detected various proteasomal subunits and components of the UPS in the acrosomal granule and cap of rat spermatids (Tengowski et al. 2007) but have only incomplete data from livestock species. A possible candidate for proteasome anchoring molecule in the acrosomal membranes is immunophilin FKBP38, shown to tether proteasomes to mitochondrial membranes (Nakagawa et al. 2007). The FKBP38 protein is incorporated in a model recently proposed to explain the degradation of UCP2 protein by proteasomes tethered to mitochondrial outer membrane (Azzu \& Brand 2010).

We do not know to what extent the subunit composition of the sperm 20S proteasomes, and of the sperm 195 regulatory complex, differs from somatic cell proteasomes. A clue is the presence of inducible 205 $\beta$-type subunits in boar spermatozoa (Sutovsky et al. 2004). Are the alternatively capped PA28 and PA200 proteasomes also present in sperm proteasomes? If so, can such proteasomes degrade zona proteins on contact, and without the need for zona protein ubiquitination? We already know that PA200 is essential for mouse spermatogenesis (Khor et al. 2006) and that ubiquitinated proteins are present in the pig zona (Zimmerman et al. 2011) and sea urchin VC (Yokota \& Sawada 2007 b). Does ubiquitination of acrosomal proteins or zona surface occur de novo after the completion of sperm biogenesis, e.g. during capacitation and/or AE? As summarized above, the E1, E2, and E3 type enzymes are present in the sperm acrosome. Considering the presence of ATP, de novo ubiquitination of sperm and zona substrates is plausible within the zona-bound acrosomal shroud, although it may be difficult to probe for it.
Could sperm proteasomes be targeted to elicit a contraceptive effect? Considering the unique cell surface exposure of sperm proteasome and their documented sensitivity to antibodies and non-permeant proteasomal inhibitors, proteasome-blocking contraceptives for human, pet, and wildlife-control use could be developed. An efficient human/wildlife contraceptive vaccine has been developed using purified porcine zona proteins (Gupta et al. 1993). The same thinking could be applied to sperm antigen-based contraceptives. Consistent with this idea, the proteasome-binding anti-sperm antibodies are present in the seminal plasma of autoimmune-infertile men (Bohring \& Krause 2003).

\section{Conclusions}

Altogether, evidence reviewed here demonstrates that sperm proteasomes are essential for the success of mammalian fertilization. While initially focusing on sperm-VC/ZP penetration, research on the sperm UPS indicates involvement in other steps of the fertilization process, starting with capacitation and $\mathrm{AE}$, and extending to and beyond sperm incorporation in the oocyte cytoplasm. Therefore, there is no surprise that the aberrations of transcriptome and proteome of the UPS have been found in the spermatozoa of infertile men (de Mateo et al. 2007, Platts et al. 2007). Future challenges include deciphering the subunit composition of sperm proteasomes, revealing how they become integrated in sperm acrosomal structures during spermiogenesis, understanding how the UPS and proteasomes regulate sperm capacitation and zona-induced $\mathrm{AE}$, examining correlation between sperm proteasome-associated enzymatic activities and fertility in men and male animals, and developing protocols that will improve sperm capacitation, oocyte maturation, and IVF for the purpose of human infertility treatment and commercial embryo transfer in livestock species. Therefore, improvements in human infertility diagnostics and treatment, contraception, livestock IVF and artificial insemination, and embryo transfer could be achieved through deciphering and modulation of sperm and zygote proteasome function.

\section{Declaration of interest}

The author declares that there is no conflict of interest that could be perceived as prejudicing the impartiality of this review.

\section{Funding}

Work from our laboratory, reviewed here, was supported by National Research Initiative Competitive Grants no. 2007-3520318274 and no. 2011-67015-20025 from the USDA National Institute of Food and Agriculture and seed funding from the Food for the 21st Century Program of the University of Missouri. 


\section{Acknowledgements}

I would like to thank my current associates and graduate students who contributed to research reviewed in this paper: Dr Gaurishankar Manandhar, Dr Young-Joo Yi, Miriam Sutovsky, Shawn Zimmerman, and Chelsey Kennedy. Clerical assistance of Ms Kathy Craighead is much appreciated. I would like to thank my colleagues and collaborators, Drs Randall Prather (University of Missouri), Billy N Day (University of Missouri), Kevin Wells (University of Missouri), Kathy L Sharpe-Timms (University of Missouri), Gary F Clark (University of Missouri), Richard Oko (Queen's University, Kingston, ON), Satish K Gupta (National Institute of Immunology, New Delhi), Mike Powell (Morehouse School of Medicine), David Miller (University of Illinois, Champaign-Urbana), Věra Jonáková (Institute of Biotechnology Academy of Sciences of the Czech Republic), Vanesa Rawe (REPROTEC, Buenos Aires), Fred van Leeuwen (Maastricht University), and Andrej Susor (Institute of Animal Physiology \& Genetics, Academy of Sciences of the Czech Republic) for their support. Special thanks are addressed to Dr Simon Wing (McGill University) for sharing his data on Usp $2^{-/-}$mouse.

\section{References}

Arcelay E, Salicioni AM, Wertheimer E \& Visconti PE 2008 Identification of proteins undergoing tyrosine phosphorylation during mouse sperm capacitation. International Journal of Developmental Biology $\mathbf{5 2}$ 463-472. (doi:10.1387/ijdb.072555ea)

Austin CR \& Bishop MW 1958 Role of the rodent acrosome and perforatorium in fertilization. Proceedings of the Royal Society of London. Series B. Biological Sciences 149 241-248. (doi:10.1098/rspb. 1958.0066)

Azzu V \& Brand MD 2010 Degradation of an intramitochondrial protein by the cytosolic proteasome. Journal of Cell Science 123 578-585. (doi:10. $1242 / j$ js.060004)

Baarends WM, van der Laan R \& Grootegoed JA 2000 Specific aspects of the ubiquitin system in spermatogenesis. Journal of Endocrinological Investigation 23 597-604.

Baba T, Azuma S, Kashiwabara S \& Toyoda Y 1994 Sperm from mice carrying a targeted mutation of the acrosin gene can penetrate the oocyte zona pellucida and effect fertilization. Journal of Biological Chemistry $26931845-31849$.

Bailey JL 2010 Factors regulating sperm capacitation. Systems Biology in Reproductive Medicine 56 334-348. (doi:10.3109/19396368.2010. 512377)

Baker MA, Hetherington L, Reeves G, Muller J \& Aitken RJ 2008 The rat sperm proteome characterized via IPG strip prefractionation and LC-MS/MS identification. Proteomics 8 2312-2321. (doi:10.1002/ pmic.200700876)

Baker MA, Smith ND, Hetherington L, Taubman K, Graham ME, Robinson PJ \& Aitken RJ 2010 Label-free quantitation of phosphopeptide changes during rat sperm capacitation. Journal of Proteome Research 9 718-729. (doi:10.1021/pr900513d)

Bedard N, Yang Y, Gregory M, Cyr DG, Suzuki J, Yu X, Chian RC, Hermo L, O'Flaherty C, Smith CE et al. 2011 Mice lacking the USP2 deubiquitinating enzyme have severe male subfertility associated with defects in fertilization and sperm motility. Biology of Reproduction [in press]. (doi:10.1095/biolreprod.110.088542)

Bedford JM 1998 Mammalian fertilization misread? Sperm penetration of the eutherian zona pellucida is unlikely to be a lytic event Biology of Reproduction 59 1275-1287. (doi:10.1095/biolreprod59.6.1275)

Bedford JM 2008 Puzzles of mammalian fertilization - and beyond. International Journal of Developmental Biology 52 415-426. (doi:10. 1387/ijdb.072551jb)
Bohring C \& Krause W 2003 Characterization of spermatozoa surface antigens by antisperm antibodies and its influence on acrosomal exocytosis. American Journal of Reproductive Immunology $\mathbf{5 0}$ 411-419. (doi:10.1034/j.1600-0897.2003.00103.x)

Chakravarty S, Bansal P, Sutovsky P \& Gupta SK 2008 Role of proteasomal activity in the induction of acrosomal exocytosis in human spermatozoa. Reproductive Biomedicine Online 16 391-400. (doi:10.1016/S14726483(10)60601-3)

Choi YJ, Uhm SJ, Song SJ, Song H, Park JK, Kim T, Park C \& Kim JH 2008 Cytochrome $C$ upregulation during capacitation and spontaneous acrosome reaction determines the fate of pig sperm cells: linking proteome analysis. Journal of Reproduction and Development 54 68-83. (doi:10.1262/jrd.19116)

Ciechanover A 2009 Tracing the history of the ubiquitin proteolytic system: the pioneering article. Biochemical and Biophysical Research Communications 387 1-10. (doi:10.1016/j.bbrc.2009.06.065)

Coux O, Nothwang HG, Silva Pereira I, Recillas Targa F, Bey F \& Scherrer K 1994 Phylogenic relationships of the amino acid sequences of prosome (proteasome, MCP) subunits. Molecular \& General Genetics 245 769-780. (doi:10.1007/BF00297284)

Diaz ES, Kong M \& Morales P 2007 Effect of fibronectin on proteasome activity, acrosome reaction, tyrosine phosphorylation and intracellular calcium concentrations of human sperm. Human Reproduction 22 1420-1430. (doi:10.1093/humrep/dem023)

Ellederova Z, Halada P, Man P, Kubelka M, Motlik J \& Kovarova H 2004 Protein patterns of pig oocytes during in vitro maturation. Biology of Reproduction 71 1533-1539. (doi:10.1095/biolreprod.104.030304)

Gadella BM \& Visconti PE 2006 Regulation of capacitation. In The Sperm Cell, pp 134-169. Eds C De Jonge \& CL Barratt. Cambridge, UK: Cambridge University Press.

Gerton G 2002 Function of the sperm acrosome. In Fertilization, pp 265-302. Ed. D Hardy. San Diego: Academic Press.

Geussova G, Kalab P \& Peknicova J 2002 Valosine containing protein is a substrate of cAMP-activated boar sperm tyrosine kinase. Molecular Reproduction and Development 63 366-375. (doi:10.1002/mrd.10156)

Glickman MH \& Ciechanover A 2002 The ubiquitin-proteasome proteolytic pathway: destruction for the sake of construction. Physiological Reviews 82 373-428. (doi:10.1152/physrev.00027.2001)

Green DP 1987 Mammalian sperm cannot penetrate the zona pellucida solely by force. Experimental Cell Research 169 31-38. (doi:10.1016/ 0014-4827(87)90221-7)

Gupta SK, Bagavant H, Chadha K, Gupta M, Yurewicz EC \& Sacco AG 1993 Mapping of immunogenic domains on porcine zona pellucida 3 alpha and beta glycoproteins by murine monoclonal antibodies. American Journal of Reproductive Immunology 30 95-100.

Guterman A \& Glickman MH 2004 Deubiquitinating enzymes are IN/(trinsic to proteasome function). Current Protein \& Peptide Science 5 201-211. (doi:10.2174/1389203043379756)

Hedrick JL 2008 Anuran and pig egg zona pellucida glycoproteins in fertilization and early development. International Journal of Developmental Biology 52 683-701. (doi:10.1387/ijdb.082580jh)

Hermo L, Pelletier RM, Cyr DG \& Smith CE 2010 Surfing the wave, cycle, life history, and genes/proteins expressed by testicular germ cells. Part 4 : intercellular bridges, mitochondria, nuclear envelope, apoptosis, ubiquitination, membrane/voltage-gated channels, methylation/acetylation, and transcription factors. Microscopy Research and Technique $\mathbf{7 3}$ 364-408. (doi:10.1002/jemt.20783)

Jin M, Fujiwara E, Kakiuchi Y, Okabe M, Satouh Y, Baba SA, Chiba K \& Hirohashi N 2011 Most fertilizing mouse spermatozoa begin their acrosome reaction before contact with the zona pellucida during in vitro fertilization. PNAS 108 4892-4896. (doi:10.1073/pnas.1018202108)

Kato JY \& Yoneda-Kato N 2009 Mammalian COP9 signalosome. Genes to Cells 14 1209-1225. (doi:10.1111/j.1365-2443.2009.01349.x)

Kawano N, Kang W, Yamashita M, Koga Y, Yamazaki T, Hata T, Miyado K \& Baba T 2010 Mice lacking two sperm serine proteases, ACR and PRSS21, are subfertile, but the mutant sperm are infertile in vitro. Biology of Reproduction 83 359-369. (doi:10.1095/biolreprod.109.083089)

Khor B, Bredemeyer AL, Huang CY, Turnbull IR, Evans R, Maggi LB Jr, White JM, Walker LM, Carnes K, Hess RA et al. 2006 Proteasome activator PA200 is required for normal spermatogenesis. Molecular and Cellular Biology 26 2999-3007. (doi:10.1128/MCB.26.8.2999-3007. 2006) 
Kim ST, Zhang K, Dong J \& Lord EM 2006 Exogenous free ubiquitin enhances lily pollen tube adhesion to an in vitro stylar matrix and may facilitate endocytosis of SCA. Plant Physiology 142 1397-1411. (doi:10. 1104/pp.106.086801)

Kloetzel PM \& Ossendorp F 2004 Proteasome and peptidase function in MHC-class-I-mediated antigen presentation. Current Opinion in Immunology 16 76-81. (doi:10.1016/j.coi.2003.11.004)

Kong M, Diaz ES \& Morales P 2009 Participation of the human sperm proteasome in the capacitation process and its regulation by protein kinase A and tyrosine kinase. Biology of Reproduction 80 1026-1035. (doi:10.1095/biolreprod.108.073924)

Kurihara LJ, Semenova E, Levorse JM \& Tilghman SM 2000 Expression and functional analysis of Uch-L3 during mouse development. Molecular and Cellular Biology 20 2498-2504. (doi:10.1128/MCB.20.7.24982504.2000)

Kwon J, Mochida K, Wang YL, Sekiguchi S, Sankai T, Aoki S, Ogura A, Yoshikawa Y \& Wada K 2005 Ubiquitin C-terminal hydrolase L-1 is essential for the early apoptotic wave of germinal cells and for sperm quality control during spermatogenesis. Biology of Reproduction $\mathbf{7 3}$ 29-35. (doi:10.1095/biolreprod.104.037077)

Kwon J, Sekiguchi S, Wang YL, Setsuie R, Yoshikawa Y \& Wada K 2006 The region-specific functions of two ubiquitin C-terminal hydrolase isozymes along the epididymis. Experimental Animals 55 35-43. (doi:10.1538/ expanim.55.35)

van Leeuwen FW, de Kleijn DP, van den Hurk HH, Neubauer A, Sonnemans MA, Sluijs JA, Koycu S, Ramdjielal RD, Salehi A, Martens GJ et al. 1998 Frameshift mutants of beta amyloid precursor protein and ubiquitin-B in Alzheimer's and Down patients. Science $\mathbf{2 7 9}$ 242-247. (doi:10.1126/science.279.5348.242)

van Leeuwen FW, Kros JM, Kamphorst W, van Schravendijk C \& de Vos RA 2006 Molecular misreading: the occurrence of frameshift proteins in different diseases. Biochemical Society Transactions 34 738-742. (doi:10.1042/BST0340738)

Lerer-Goldshtein T, Bel S, Shpungin S, Pery E, Motro B, Goldstein RS, Bar-Sheshet SI, Breitbart H \& Nir U 2010 TMF/ARA160: a key regulator of sperm development. Developmental Biology 348 12-21. (doi:10.1016/ j.ydbio.2010.07.033)

Massicotte L, Coenen K, Mourot M \& Sirard MA 2006 Maternal housekeeping proteins translated during bovine oocyte maturation and early embryo development. Proteomics 6 3811-3820. (doi:10.1002/ pmic.200500803)

de Mateo S, Martinez-Heredia J, Estanyol JM, Dominguez-Fandos D, VidalTaboada JM, Ballesca JL \& Oliva R 2007 Marked correlations in protein expression identified by proteomic analysis of human spermatozoa. Proteomics 7 4264-4277. (doi:10.1002/pmic.200700521)

Mochida K, Tres LL \& Kierszenbaum AL 2000 Structural features of the $26 \mathrm{~S}$ proteasome complex isolated from rat testis and sperm tail. Molecular Reproduction and Development 57 176-184. (doi:10.1002/10982795(200010)57:2 <176::AID-MRD9> 3.0.CO;2-O)

Moore K, Lovercamp K, Feng D, Antelman J, Sutovsky M, Manandhar G, van Leyen K, Safranski T \& Sutovsky P 2010 Altered epididymal sperm maturation and cytoplasmic droplet migration in subfertile male Alox 15 mice. Cell and Tissue Research 340 569-581. (doi:10.1007/s00441-0100972-x)

Morales P, Kong M, Pizarro E \& Pasten C 2003 Participation of the sperm proteasome in human fertilization. Human Reproduction 18 1010-1017. (doi:10.1093/humrep/deg111)

Morales P, Pizarro E, Kong M \& Jara M 2004 Extracellular localization of proteasomes in human sperm. Molecular Reproduction and Development 68 115-124. (doi:10.1002/mrd.20052)

Morales P, Diaz ES \& Kong M 2007 Proteasome activity and its relationship with protein phosphorylation during capacitation and acrosome reaction in human spermatozoa. Society of Reproduction and Fertility Supplement 65 269-273.

Mtango NR, Sutovsky M, Zhong Z, VandeVoort CA, Latham KE \& Sutovsky P 2009 Roles of deubiquitnating enzymes UCHL1 and UCHL3 in oocyte maturation, fertilization and zygotic development. Biology of Reproduction 81 (Special Issue) 329.

Nakagawa T, Shirane M, lemura S, Natsume T \& Nakayama KI 2007 Anchoring of the $26 \mathrm{~S}$ proteasome to the organellar membrane by FKBP38. Genes to Cells 12 709-719. (doi:10.1111/j.1365-2443.2007. 01086.x)
Naz RK \& Dhandapani L 2010 Identification of human sperm proteins that interact with human zona pellucida3 (ZP3) using yeast two-hybrid system. Journal of Reproductive Immunology 84 24-31. (doi:10.1016/j. jri.2009.10.006)

Olds-Clarke P 2003 Unresolved issues in mammalian fertilization. International Review of Cytology 232 129-184. (doi:10.1016/S00747696(03)32004-2)

Pasten C, Morales P \& Kong M 2005 Role of the sperm proteasome during fertilization and gamete interaction in the mouse. Molecular Reproduction and Development 71 209-219. (doi:10.1002/mrd.20280)

Peng J, Schwartz D, Elias JE, Thoreen CC, Cheng D, Marsischky G, Roelofs J, Finley D \& Gygi SP 2003 A proteomics approach to understanding protein ubiquitination. Nature Biotechnology 21 921-926. (doi:10.1038/nbt849)

Platts AE, Dix DJ, Chemes HE, Thompson KE, Goodrich R, Rockett JC, Rawe VY, Quintana S, Diamond MP, Strader LF et al. 2007 Success and failure in human spermatogenesis as revealed by teratozoospermic RNAs. Human Molecular Genetics 16 763-773. (doi:10.1093/hmg/ ddm012)

de Pril R, Fischer DF, Maat-Schieman ML, Hobo B, de Vos RA, Brunt ER, Hol EM, Roos RA \& van Leeuwen FW 2004 Accumulation of aberrant ubiquitin induces aggregate formation and cell death in polyglutamine diseases. Human Molecular Genetics 13 1803-1813. (doi:10.1093/hmg/ ddh188)

Rawe VY, Diaz ES, Abdelmassih R, Wojcik C, Morales P, Sutovsky P \& Chemes HE 2008 The role of sperm proteasomes during sperm aster formation and early zygote development: implications for fertilization failure in humans. Human Reproduction 23 573-580. (doi:10.1093/ humrep/dem385)

Rechsteiner M \& Hill CP 2005 Mobilizing the proteolytic machine: cell biological roles of proteasome activators and inhibitors. Trends in Cell Biology 15 27-33. (doi:10.1016/j.tcb.2004.11.003)

Rivkin E, Kierszenbaum AL, Gil M \& Tres LL 2009 Rnf19a, a ubiquitin protein ligase, and Psmc3, a component of the $26 \mathrm{~S}$ proteasome, tether to the acrosome membranes and the head-tail coupling apparatus during rat spermatid development. Developmental Dynamics 238 1851-1861. (doi:10.1002/dvdy.22004)

Rodriguez CI \& Stewart CL 2007 Disruption of the ubiquitin ligase HERC4 causes defects in spermatozoon maturation and impaired fertility. Developmental Biology 312 501-508. (doi:10.1016/j.ydbio.2007.09. 053)

Rodriguez-Miranda E, Buffone MG, Edwards SE, Ord TS, Lin K, Sammel MD, Gerton GL, Moss SB \& Williams CJ 2008 Extracellular adenosine $5^{\prime}$-triphosphate alters motility and improves the fertilizing capability of mouse sperm. Biology of Reproduction 79 164-171. (doi:10.1095/biolreprod.107.065565)

Roest HP, van Klaveren J, de Wit J, van Gurp CG, Koken MH, Vermey M, van Roijen JH, Hoogerbrugge JW, Vreeburg JT, Baarends WM et al. 1996 Inactivation of the HR6B ubiquitin-conjugating DNA repair enzyme in mice causes male sterility associated with chromatin modification. Cell 86 799-810. (doi:10.1016/S0092-8674(00)80154-3)

Saigoh K, Wang YL, Suh JG, Yamanishi T, Sakai Y, Kiyosawa H, Harada T, Ichihara N, Wakana S, Kikuchi T et al. 1999 Intragenic deletion in the gene encoding ubiquitin carboxy-terminal hydrolase in gad mice. Nature Genetics 23 47-51. (doi:10.1038/12647)

Saitoh Y, Sawada H \& Yokosawa H 1993 High-molecular-weight protease complexes (proteasomes) of sperm of the ascidian, Halocynthia roretzi: isolation, characterization, and physiological roles in fertilization. Developmental Biology 158 238-244. (doi:10.1006/dbio.1993.1182)

Sakai N, Sawada H \& Yokosawa H 2003 Extracellular ubiquitin system implicated in fertilization of the ascidian, Halocynthia roretzi: isolation and characterization. Developmental Biology 264 299-307. (doi:10. 1016/j.ydbio.2003.07.016)

Sakai N, Sawada MT \& Sawada H 2004 Non-traditional roles of ubiquitinproteasome system in fertilization and gametogenesis. International Journal of Biochemistry \& Cell Biology 36 776-784. (doi:10.1016/ S1357-2725(03)00263-2)

Sanchez R, Deppe M, Schulz M, Bravo P, Villegas J, Morales P \& Risopatron J 2011 Participation of the sperm proteasome during in vitro fertilisation and the acrosome reaction in cattle. Andrologia 43 114-120. (doi:10.1111/j.1439-0272.2009.01031.x) 
Sawada H, Pinto MR \& De Santis R 1998 Participation of sperm proteasome in fertilization of the phlebobranch ascidian Ciona intestinalis. Molecular Reproduction and Development 50 493-498. (doi:10.1002/ (SICl)1098-2795(199808)50:4 < 493::AID-MRD13>3.0.CO;2-3)

Sawada H, Sakai N, Abe Y, Tanaka E, Takahashi Y, Fujino J, Kodama E, Takizawa S \& Yokosawa H 2002a Extracellular ubiquitination and proteasome-mediated degradation of the ascidian sperm receptor. PNAS 99 1223-1228. (doi:10.1073/pnas.032389499)

Sawada H, Takahashi Y, Fujino J, Flores SY \& Yokosawa H 2002b Localization and roles in fertilization of sperm proteasomes in the ascidian Halocynthia roretzi. Molecular Reproduction and Development 62 271-276. (doi:10.1002/mrd.10089)

Sekiguchi S, Kwon J, Yoshida E, Hamasaki H, Ichinose S, Hideshima M, Kuraoka M, Takahashi A, Ishii Y, Kyuwa S et al. 2006 Localization of ubiquitin C-terminal hydrolase L1 in mouse ova and its function in the plasma membrane to block polyspermy. American Journal of Pathology 169 1722-1729. (doi:10.2353/ajpath.2006.060301)

Stone M, Hartmann-Petersen R, Seeger M, Bech-Otschir D, Wallace M \& Gordon C 2004 Uch2/Uch37 is the major deubiquitinating enzyme associated with the $26 \mathrm{~S}$ proteasome in fission yeast. Journal of Molecular Biology 344 697-706. (doi:10.1016/j.jmb.2004.09.057)

Sun QY, Fuchimoto D \& Nagai T 2004 Regulatory roles of ubiquitinproteasome pathway in pig oocyte meiotic maturation and fertilization. Theriogenology 62 245-255. (doi:10.1016/j.theriogenology.2003.10. 015)

Susor A, Liskova L, Toralova T, Pavlok A, Pivonkova K, Karabinova P, Lopatarova M, Sutovsky P \& Kubelka M 2010 Role of ubiquitin C-terminal hydrolase-L1 in antipolyspermy defense of mammalian oocytes. Biology of Reproduction 82 1151-1161. (doi:10.1095/biolreprod.109.081547)

Sutovsky P 2009 Sperm-egg adhesion and fusion in mammals. Expert Reviews in Molecular Medicine 11 e11. (doi:10.1017/S1462399409001045)

Sutovsky P 2010 Fertilization. In Reproductive Endocrinology and Infertility: the Practical Clinic and Laboratory. Eds D Carrell \& $M$ Peterson. Totowa, NJ: The Humana Press.

Sutovsky P, McCauley TC, Sutovsky M \& Day BN 2003 Early degradation of paternal mitochondria in domestic pig (Sus scrofa) is prevented by selective proteasomal inhibitors lactacystin and MG132. Biology of Reproduction 68 1793-1800. (doi:10.1095/biolreprod.102.012799)

Sutovsky P, Manandhar G, McCauley TC, Caamano JN, Sutovsky M, Thompson WE \& Day BN 2004 Proteasomal interference prevents zona pellucida penetration and fertilization in mammals. Biology of Reproduction 71 1625-1637. (doi:10.1095/biolreprod.104.032532)

Tanaka K 2009 The proteasome: overview of structure and functions. Proceedings of the Japan Academy. Series B, Physical and Biological Sciences 85 12-36. (doi:10.2183/pjab.85.12)

Tengowski MW, Feng D, Sutovsky M \& Sutovsky P 2007 Differential expression of genes encoding constitutive and inducible $20 S$ proteasomal core subunits in the testis and epididymis of theophylline- or 1,3dinitrobenzene-exposed rats. Biology of Reproduction 76 149-163. (doi:10.1095/biolreprod.106.053173)

Tipler CP, Hutchon SP, Hendil K, Tanaka K, Fishel S \& Mayer RJ 1997 Purification and characterization of $26 \mathrm{~S}$ proteasomes from human and mouse spermatozoa. Molecular Human Reproduction 3 1053-1060. (doi:10.1093/molehr/3.12.1053)

Voges D, Zwickl P \& Baumeister W 1999 The 26S proteasome: a molecular machine designed for controlled proteolysis. Annual Review of Biochemistry 68 1015-1068. (doi:10.1146/annurev.biochem.68.1.1015)

Wang H, Song C, Duan C, Shi W, Li C, Chen D \& Wang Y 2002 Effects of ubiquitin-proteasome pathway on mouse sperm capacitation, acrosome reaction and in vitro fertilization. Chinese Science Bulletin 47 127-132. (doi:10.1360/02tb9029)

Wilkinson CR, Ferrell K, Penney M, Wallace M, Dubiel W \& Gordon C 2000 Analysis of a gene encoding Rpn10 of the fission yeast proteasome reveals that the polyubiquitin-binding site of this subunit is essential when Rpn12/Mts3 activity is compromised. Journal of Biological Chemistry 275 15182-15192. (doi:10.1074/jbc.275.20.15182)

Wing SS, Bedard N, Morales C, Hingamp P \& Trasler J 1996 A novel rat homolog of the Saccharomyces cerevisiae ubiquitin-conjugating enzymes UBC4 and UBC5 with distinct biochemical features is induced during spermatogenesis. Molecular and Cellular Biology 16 4064-4072.

Yanagimachi R 1994 Mammalian fertilization. In The Physiology of Reproduction, 2nd edn, pp 189-317. Eds E Knobil \& J Neill. New York: Raven Press.

Yanagimachi R 2009 Germ cell research: a personal perspective. Biology of Reproduction 80 204-218. (doi:10.1095/biolreprod.108.071993)

Yi YJ, Manandhar G, Oko RJ, Breed WG \& Sutovsky P 2007a Mechanism of sperm-zona pellucida penetration during mammalian fertilization: $26 \mathrm{~S}$ proteasome as a candidate egg coat lysin. Society of Reproduction and Fertility Supplement 63 385-408.

Yi YJ, Manandhar G, Sutovsky M, Li R, Jonakova V, Oko R, Park CS, Prather RS \& Sutovsky P 2007b Ubiquitin C-terminal hydrolase-activity is involved in sperm acrosomal function and anti-polyspermy defense during porcine fertilization. Biology of Reproduction 77 780-793. (doi:10.1095/biolreprod.107.061275)

Yi YJ, Manandhar G, Sutovsky M, Jonakova V, Park CS \& Sutovsky P 2009a Inhibition of $19 S$ proteasomal regulatory complex subunit PSMD8 increases polyspermy during porcine fertilization in vitro. Journal of Reproductive Immunology 84 154-163. (doi:10.1016/j.jri.2009.11.002)

Yi YJ, Park CS, Kim ES, Song ES, Jeong JH \& Sutovsky P $2009 b$ Spermsurface ATP in boar spermatozoa is required for fertilization: relevance to sperm proteasomal function. Systems Biology in Reproductive Medicine 55 85-96. (doi:10.1080/19396360802699074)

Yi YJ, Manandhar G, Sutovsky M, Zimmerman SW, Jonakova V, van Leeuwen FW, Oko R, Park CS \& Sutovsky P 2010 Interference with the 195 proteasomal regulatory complex subunit PSMD4 on the sperm surface inhibits sperm-zona pellucida penetration during porcine fertilization. Cell and Tissue Research 341 325-340. (doi:10.1007/ s00441-010-0988-2)

Yokota N \& Sawada H 2007a Effects of proteasome inhibitors on fertilization of the sea urchin Anthocidaris crassispina. Biological \& Pharmaceutical Bulletin 30 1332-1335. (doi:10.1248/bpb.30.1332)

Yokota N \& Sawada H 2007b Sperm proteasomes are responsible for the acrosome reaction and sperm penetration of the vitelline envelope during fertilization of the sea urchin Pseudocentrotus depressus. Developmental Biology 308 222-231. (doi:10.1016/j.ydbio.2007.05.025)

Yokota N, Harada Y \& Sawada H 2010 Identification of testis-specific ubiquitin-conjugating enzyme in the ascidian Ciona intestinalis. Molecular Reproduction and Development 77 640-647. (doi:10.1002/ mrd.21198)

Young P, Deveraux Q, Beal RE, Pickart CM \& Rechsteiner M 1998 Characterization of two polyubiquitin binding sites in the $26 \mathrm{~S}$ protease subunit 5a. Journal of Biological Chemistry 273 5461-5467. (doi:10. 1074/jbc.273.10.5461)

Zimmerman S \& Sutovsky P 2009 The sperm proteasome during sperm capacitation and fertilization. Journal of Reproductive Immunology $\mathbf{8 3}$ 19-25. (doi:10.1016/j.jri.2009.07.006)

Zimmerman SW, Manandhar G, Yi Y-J, Gupta SK, Sutovsky M, Odhiambo JF, Powell MD, Miller DJ \& Sutovsky P 2011 Sperm proteasomes degrade sperm receptor on the egg zona pellucida during mammalian fertilization. PLOS ONE 6 e17256. (doi:10.1371/journal. pone.0017256)

Received 11 February 2011

First decision 31 March 2011

Revised manuscript received 11 May 2011

Accepted 20 May 2011 